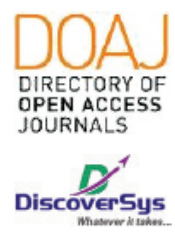

Published by DiscoverSys

\title{
Gambaran hasil pemeriksaan endoskopi pada pasien dispepsia di Rumah Sakit Umum Pusat (RSUP) Sanglah tahun 2015
}

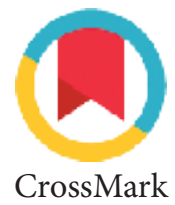

\author{
Anak Agung Gde Waisampayana Putra, ${ }^{1{ }^{*}}$ I Dewa Nyoman Wibawa ${ }^{2}$
}

\section{ABSTRACT}

Background: Dyspepsia is recurrent and persistent pain or discomfort in the upper abdomen. Dyspepsia can be divided into two, which are organic dyspepsia and functional dyspepsia, respectively. Endoscopy is one of the recommended diagnostic tools for dyspepsia. This study aims to describe the endoscopic results in dyspeptic patients at Sanglah General Hospital.

Method: The quantitative cross-sectional descriptive study design was used. This study used secondary data from medical records. The sample population of this study was patients with dyspepsia who undergone endoscopy procedure at the Sanglah Central General Hospital in 2015 with a total sampling method that resulted in 260 samples. Data were analyzed using SPSS version 21 for Windows.
Results: The sex of the respondents involved in this study were male (50.8\%) and female (49.2\%), which have almost the same percentage. Nearly half of the study respondents were 41-60 years old (47.7\%). About 92.3\%, patients were organic dyspepsia and $7.7 \%$, functional dyspepsia. While the most diagnosed endoscopic examination results were gastritis (40.0\%) and found in the young age group ( $\leq 64$ years).

Conclusion: Patients with symptoms of dyspepsia are mostly male, young adults, have organic dyspepsia, and the picture of endoscopic examination is dominated by gastritis at a young age.

Keywords: dyspepsia, endoscopy, clinical features, Sanglah General Hospital Cite this Article: Putra, A.A.G.W., Wibawa, I.D.N. 2020. Gambaran hasil pemeriksaan endoskopi pada pasien dispepsia di Rumah Sakit Umum Pusat (RSUP) Sanglah tahun 2015. Intisari Sains Medis 11(1): 35-40. D0I: 10.15562/ism.v11i1.529

ABSTRAK

Latar Belakang: Dispepsia adalah nyeri yang berulang dan menetap atau rasa tidak nyaman di daerah perut bagian atas. Dispepsia dapat dibagi menjadi dua yaitu dispepsia organik dan dispepsia fungsional. Endoskopi merupakan salah satu alat diagnostik yang di rekomendasikan untuk diagnosis dispepsia. Penelitian ini bertujuan untuk mengambarkan hasil endoskopi pada pasien dispepsia di RSUP Sanglah.

Metode: Desain studi penelitian deskriptif kuantitatif cross sectional dengan menggunakan data sekunder dari rekam medis. Populasi sampel penelitian ini adalah pasien dispepsia yang melakukan endoskopi di Rumah Sakit Umum Pusat Sanglah Tahun 2015 dengan metode Total sampling yang menghasilkan 260 sampel. Data dianalisis menggunakan SPSS 21.
Hasil: Jenis kelamin responden yang terlibat pada penelitian ini adalah laki-laki $(50,8 \%)$ dan perempuan $(49,2 \%)$ dimana memiliki persentase yang hampir sama. Hampir setengah responden penelitian berusia $41-60$ tahun $(47,7 \%)$. Sekitar $92,3 \%$, pasien merupakan dispepsia organik dan 7,7\%, merupakan dispepsia fungsional. Sedangkan diagnosis terbanyak pada hasil pemeriksaan endoskopi adalah gastritis $(40,0 \%)$ dan ditemukan pada kelompok usia muda ( $\leq 64$ tahun).

Kesimpulan: Pasien dengan gejala dispepsia sebagian besar berjenis kelamin laki-laki, berusia dewasa muda, memiliki dispepsia organik, dan gambaran pemeriksaan endoskopi didominasi oleh gastritis pada usia muda.
Bali, Indonesia

${ }^{2}$ Departemen IImu Penyakit Dalam, Fakultas Kedokteran, Universitas Udayana, RSUP Sanglah, Bali, Indonesia

\section{*Korespondensi:}

Anak Agung Gde Waisampayana Putra; Mahasiswa Program Studi Pendidikan Dokter, Fakultas Kedokteran, Universitas Udayana, Bali, Indonesia; sampayana@gmail.com

Diterima: 17-06-2019

Disetujui: 03-01-2020

Diterbitkan: 01-04-2020
Kata kunci: dispepsia, endoskopi, gambaran klinis, RSUP Sanglah.

Cite Pasal Ini: Putra, A.A.G.W., Wibawa, I.D.N. 2020. Gambaran hasil pemeriksaan endoskopi pada pasien dispepsia di Rumah Sakit Umum Pusat (RSUP) Sanglah tahun 2015. Intisari Sains Medis 11(1): 35-40. D0I: 10.15562/ism.v11i1.529

\section{PENDAHULUAN}

Dispepsia fungsional menurut kriteria Rome III tahun 2006 mendefinisikan adanya gejala dispepsia seperti nyeri atau rasa tidak nyaman abdominal pada regio gastroduodenal yang berlangsung setidaknya 3 bulan, dengan onset gejala timbul
6 bulan sebelum diagnosis, tanpa adanya penyakit organik, sistemik, atau metabolik yang menyebabkan gejala dispepsia. ${ }^{1}$ Prevalensi dari dispepsia dari studi yang dilakukan oleh Mahadeva dkk adalah sebesar $496(24,3 \%)$ dengan 15,5\% diantaranya 
memiliki dispepsia sub tipe 'ulcer like', sebanyak $57 \%$ dengan dispepsia 'dysmotility-like', dan 27,7\% sisanya memiliki dispepsia dengan gejala campuran. ${ }^{2}$ Dispepsia menempati urutan ke 5 pada 10 besar penyakit pada pasien rawat jalan di Rumah Sakit Umum Daerah (RSUD) di Provinsi Bali pada tahun 2014 dan urutan no 7 dari 10 besar penyakit pada pasein rawat inap di RSUD di provinsi Bali pada tahun $2014 .^{3}$

Dispepsia dapat dibagi menjadi dua subklasifikasi yaitu dispepsia organik dan dispepsia fungsional jika kemungkinan penyakit organik telah dieksklusi. ${ }^{4}$ Dispepsia organik memiliki beberapa penyebab antara lain ulkus peptikum, neoplasma gaster-duodenum, GERD, intoleransi makanan, medikasi, pancreatic dan billiary tract disorder, gastroparesis, Irritable bowel syndrome, dan lain-lain., ${ }^{1,5}$ Sedangkan dispepsia fungsional diklasifikasikan manjadi dua kategori yaitu epigastric pain syndrome (EPS) dan postprandial distress syndrome (PDS). EPS terdiri dari nyeri intermiten atau sensasi terbakar pada epigastrium yang terjadi setidaknya satu kali dalam seminggu, dan PDS ditandai dengan rasa penuh setelah makan yang mengganggu, terjadi setelah makan dengan porsi biasa atau perasaan cepat kenyang yang menyebabkan tidak mampu menghabiskan porsi makanan normal yang terjadi setidaknya beberapa kali dalam seminggu. ${ }^{6}$

Patofisiologi dispepsia khususnya dispepsia fungsional memiliki beberapa mekanisme yaitu mekanisme proses pengosongan gaster yang tertunda, gangguan akomodasi makanan pada gaster, hipersesitivitas distensi gaster, infeksi H. Pylori, perubahan sensitivitas duodenal terhadap lipid atau asam, dan disfungsi sistem saraf pusat. ${ }^{7}$ Gejala dispeptik pada dispepsia fungsional umumnya diperburuk oleh makanan kaya lemak dikarenakan sifat lemak yang dapat meningkatkan relaksasi dan juga sensitivitas distensi dari gastrik proksimal. Selain itu, respon pergerakkan duodenal terhadap asam mengalami pengurangan pada pasien dispepsia fungsional, ${ }^{6,7}$ Disfungsi vagal eferen, juga dapat menjadi penyebab hipomotilitas antral yang dikaitkan dengan faktor psikologis. ${ }^{7}$ Beberapa faktor yang dapat menjadi faktor risiko dari terjadinya dyspepsia adalah merokok, obesitas, penggunaan NSAIDs, aspirin, bifosfonat, DMARD serta wanita dengan riwayat hormone replacement therapy. ${ }^{8}$

Penegakkan diagnosis dispepsia dilakukan dengan melakukan anamnesis, pemeriksaan fisik dan penunjang. Pada anamnesis dapat ditemukan keluhan berupa rasa penuh pada perut yang menganggu, lebih cepat kenyang, nyeri epigastrium, dan perasaan terbakar pada area epigastrium. ${ }^{79}$ Untuk menegakkan penyebab dari dispepsia, diperlukan pemeriksaan penunjang yang dapat memperlihatkan struktur dari lambung dan duodenum. Salah satu modaliyas yang dapat diandalkan adalah endoskopi. Endoskopi dapat digunakan untuk melihat kelainan dari struktur gaster sehingga diagnosis dan klasifikasi dispepsia dapat ditentukan. ${ }^{9}$

Berkaitan dengan latar belakang di atas maka studi ini dilakukan untuk mengetahui karakteristik hasil pemeriksaan endoskopi pada pasien dispepsia di RSUP Sanglah pada tahun 2015. Dengan mengetahui karakteristik hasil endoskopi maka diharapkan dapat memahami lebih dalam kecenderungan dispepsia pada kelompok populasi tertentu.

\section{METODE}

Penelitian ini menggunakan rancangan penelitian observasional deskriptif dengan pendekatan potong lintang. Penelitian dilakukan di RSUP Sanglah bulan Agustus 2016 - September 2016. Sampel diambil dengan metode total sampling dimana pasien dispepsia yang menjalani prosedur endoskopi di RSUP Sanglah pada periode penelitian diikutsertakan dalam penelitian hingga mencapai kebutuhan. Subjek dengan data rekam medis yang tidak lengkap diekslusi dari penelitian. Data yang diambil berupa data sekunder yang berasal dari catatan rekam medis pasien, dengan variabel yang diambil adalah usia, jenis kelamin, domisili, gambaran endoskopi, dan klasifikasi dispepsia.

Seluruh data penelitian yang diperoleh dari rekam medis pasien kemudian dicatat dan dianalisis. Data dianalisis dengan menggunakan piranti lunak SPSS versi 21 untuk Windows dimana ditampilkan dalam bentuk jumlah dan persentase.

\section{HASIL}

Subjek yang memenuhi kriteria inklusi dan ekslusi sehingga dapat diikutsertakan dalam studi berjumlah total 260 orang. Pasien dengan jenis kelamin lelaki mendominasi dengan persentase 50,8\% sedangkan pasien perempuan memiliki persentase 49,2\%. Pasien dikelompokkan menjadi usia di bawah 20 tahun, 20-40 tahun, 41-60 tahun dan lebih dari 60 tahun. Proporsi usia terbanyak adalah kelompok usia 41-60 tahun dengan persentase $47,4 \%$ diikuti oleh populasi berusia lebih dari 60 tahun $(30,0 \%)$ dan kelompok usia 20-40 tahun (20\%). Hanya terdapat 6 pasien yang berusia 13-19 tahun. Jumlah pasien yang berasal dari desa dan kota tidak berbeda banyak dengan selisih 22 orang (Tabel 1). 
Tabel 1 Karakteristik Demografi Pasien Dispepsia yang Menjalani Prosedut Endoskopi di RSUP Sanglah Periode April 2015-September 2016

\begin{tabular}{|c|c|c|}
\hline Variabel & Frekuensi $(n=260)$ & Presentase (\%) \\
\hline \multicolumn{3}{|l|}{ Umur (Tahun) } \\
\hline $13-19$ & 6 & 2,3 \\
\hline $20-40$ & 52 & 20,0 \\
\hline $41-60$ & 120 & 47,4 \\
\hline$>60$ & 78 & 30,0 \\
\hline \multicolumn{3}{|l|}{ Jenis Kelamin } \\
\hline Laki-laki & 128 & 49,2 \\
\hline Perempuan & 132 & 50.8 \\
\hline \multicolumn{3}{|l|}{ Domisili } \\
\hline Desa & 119 & 45,8 \\
\hline Kota & 141 & 54,2 \\
\hline \multicolumn{3}{|l|}{ Gambaran Endoskopi } \\
\hline Gastritis & 104 & 40,0 \\
\hline Hernia Hiatal & 34 & 13,0 \\
\hline Ulkus Gaster & 21 & 8,1 \\
\hline Normal & 20 & 7,7 \\
\hline Gastropati Hipertensi Portal & 18 & 6,9 \\
\hline Suspek Malignansi Duodenum & 11 & 4,2 \\
\hline Bile Reflux & 10 & 3,8 \\
\hline Esofagitis & 9 & 3,5 \\
\hline Suspek Malignansi Gaster & 7 & 2,7 \\
\hline Ulkus Duodenum & 6 & 2,3 \\
\hline Barret's Esofagus & 5 & 1,9 \\
\hline Varises Esofagus & 4 & 1,5 \\
\hline Polip Gaster & 3 & 1,2 \\
\hline Candidiasis & 2 & 0,8 \\
\hline Duodenitis & 2 & 0,8 \\
\hline Suspek Malignansi Esofagus & 2 & 0,8 \\
\hline Ulkus Esofagus & 2 & 0,8 \\
\hline \multicolumn{3}{|l|}{ Klasifikasi Dispepsia } \\
\hline Organik & 240 & 92,3 \\
\hline Fungsional & 20 & 7,7 \\
\hline
\end{tabular}

Tabel 2 Perbedaan gambaran endoskopi ada pasien dispepsia berdasarkan jenis kelamin dan usia

\begin{tabular}{lcccc}
\hline & \multicolumn{2}{c}{ Jenis Kelamin (N=260) } & \multicolumn{2}{c}{ Usia (N=260) } \\
\cline { 2 - 5 } Gambaran Endoskopi & $\begin{array}{c}\text { Laki-Laki } \\
(\mathbf{N}=\mathbf{1 3 2})\end{array}$ & $\begin{array}{c}\text { Perempuan } \\
(\mathbf{N}=\mathbf{1 2 8})\end{array}$ & $\begin{array}{c}\text { Muda (N=207) } \\
(<\mathbf{6 4} \text { tahun) }\end{array}$ & $\begin{array}{c}\text { Tua (N=53) } \\
(>\mathbf{6 4} \text { tahun) }\end{array}$ \\
\hline Gastritis & 50 & 54 & 91 & 13 \\
Hernia Hiatal & 20 & 14 & 25 & 9 \\
Ulkus Gaster & 13 & 8 & 12 & 9 \\
Normal & 8 & 12 & 17 & 3 \\
Gastropati Hipertensi Portal & 12 & 6 & 15 & 3 \\
Suspek Malignansi Duodenum & 5 & 6 & 8 & 3 \\
\hline
\end{tabular}


Tabel 2 Continue

\begin{tabular}{|c|c|c|c|c|}
\hline \multirow[b]{2}{*}{ Gambaran Endoskopi } & \multicolumn{2}{|c|}{ Jenis Kelamin ( $N=260)$} & \multicolumn{2}{|c|}{ Usia $(\mathrm{N}=\mathbf{2 6 0})$} \\
\hline & $\begin{array}{c}\text { Laki-Laki } \\
(\mathrm{N}=132)\end{array}$ & $\begin{array}{c}\text { Perempuan } \\
(\mathrm{N}=128)\end{array}$ & $\begin{array}{c}\text { Muda ( } \mathrm{N}=207) \\
(<64 \text { tahun) }\end{array}$ & $\begin{array}{l}\text { Tua ( } \mathrm{N}=53) \\
\text { (> } 64 \text { tahun) }\end{array}$ \\
\hline Bile Reflux & 4 & 6 & 9 & 1 \\
\hline Esofagitis & 3 & 6 & 7 & 2 \\
\hline Suspek Malignansi Gaster & 4 & 3 & 6 & 1 \\
\hline Ulkus Duodenum & 3 & 3 & 4 & 2 \\
\hline Barret's Esofagus & 3 & 2 & 3 & 2 \\
\hline Varises Esofagus & 2 & 2 & 4 & 0 \\
\hline Polip Gaster & 2 & 1 & 2 & 1 \\
\hline Candidiasis & 0 & 2 & 1 & 1 \\
\hline Duodenitis & 1 & 1 & 1 & 1 \\
\hline Suspek Malignansi Esofagus & 1 & 1 & 1 & 1 \\
\hline Ulkus Esofagus & 1 & 1 & 1 & 1 \\
\hline
\end{tabular}

Tabel 3 Klasifikasi Dispepsia Berdasarkan Usia

\begin{tabular}{lcc}
\hline & \multicolumn{2}{c}{ Usia $(\mathbf{N}=\mathbf{2 6 0})$} \\
\cline { 2 - 3 } Klasifikasi & $\mathbf{0 - 5 5}$ tahun $(\mathbf{N}=\mathbf{1 4 7})$ & $\mathbf{> 5 5}$ tahun $(\mathbf{N}=\mathbf{1 1 3})$ \\
\hline Organik & 133 & 107 \\
Fungsional & 14 & 6 \\
\hline
\end{tabular}

Peneliti melihat karakteristik hasil endoskopi dari pasien dispepsia. Ditemukan gambaran terbanyak adalah gastritis dengan persentase $40 \%$ dari total temuan, disusul dengan gambaran hernia hiatal $(13 \%)$, ulkus gaster $(8,1 \%)$, dan gambaran struktur normal (7,7\%). Jumlah temuan yang sedikit ditemukan dengan hanya terdapat 2 pasien dengan gambaran tersebut adalah candidiasis, duodenitis, suspek keganasan esophagus dan ulkus esophagus (Tabel 1). Berdasarkan gambaran tersebut, maka dikelompokkan jenis dispepsia menjadi organik dan fungsional dimana pasien dengan dispepsia organik mendominasi dengan persentase $92,3 \%$ sedangkan hanya terdapat 20 pasien dengan dispepsia fungsional (Tabel 1).

Peneliti melakukan tabulasi silang untuk melihat perbedaan gambaran hasil endoskopi berdasarkan jenis kelamin dan usia. Bedasarkan jenis kelamin ditemukan bahwa jumlah kelainan organik pada wanita secara umum selalu lebih banyak dibandingkan dengan lelaki, akan tetapi, pada gambaran hernia hiatal, dan gastropati hipeertensi portal persentase lelaki lebih banyak dibandingkan dengan perempuan (20 vs 14 dan 12 vs 6 ). Usia dikelompokkan ulang menjadi usia muda yaitu $<64$ tahun dan usia tua >64 tahun. Ditemukan bahwa pasien dengan usia muda (0-55 tahun) lebih banyak mengalami kelainan pada gambaran endoskopiya dibandingkan dengan usia tua yang secara tidak langsung menunjukkan bahwa dispepsia pada populasi lebih muda lebih banyak disebabkan oleh karena organik dibandingkan pada populasi tua (Tabel 2 dan 3).

\section{PEMBAHASAN}

Endoskopi merupakan salah satu modalitas yang paling sering digunakan dalam mendiagnosis kelainan peptikum pada pasien dengan sindroma dispepsia. Pemisahan katagori antara dispepsia organik dan fungsional juga didasarkan dari temuan endoskopi. ${ }^{10}$ Pasien dengan tanda "alarm" merupakan pasien yang seringkali melakukan prosedur endoskopi, dimana tanda tersebut berupa usia $>50$ tahun, adanya riwayat keluarga dengan malignansi Gastro Intestinal (GI) atas, penurunan berat badan signifikan pendarahan GI disertai dengan anemia defisiensi besi, disfagia, odynofagia, muntah persisten dan dugaan penyakit organik. Pada pasien seperti itu, endoskopi ditujukan untuk mengeklusi kemungkinan adanya malignansi, meskipun adanya tanda alarm bukan menjadi indikasi absolut untuk melakukan endoskopi. Pasien dengan penggunaan Proton Pump Inhibitor (PPI) jangka panjang dan tidak merespon pengobatan PPI juga dianjurkan untuk melakukan endoskopi. Meskipun hasil kelainan structural dari endoskopi tidak ditemukan, hal ini masih dapat memberikan keuntungan bagi pasien dimana terjadi penurunan kecemasan secara signifikan dan peningkatan 
kepuasan pasien yang juga secara tidak langsung dapat memperbaiki gejala dispepsia terutama pada dispepsia fungsional. ${ }^{11}$

Dalam studi ini ditemukan bahwa penderita dispepsia didominasi oleh perempuan, dan populasi berusia 41-60 tahun. Gambaran demografis ini sesuai dengan studi yang dilakukan oleh Faintuch dkk yang menemukan dominasi jenis kelamin perempuan dan usia $<58$ tahun pada penderita dispepsia yang menjalani endoskopi. Hal ini dikaitkan dengan kecenderungan stress pada wanita yang lebih mudah menimbulkan gejala dispepsia dibandingkan pada pria. Usia muda lebih banyak ditemukan karena diasumsikan populasi yang lebih muda memiliki aktivitas yang lebih banyak dibandingkan dengan populasi tua yang menyebabkan kacaunya jadwal makan mereka. ${ }^{12}$ Hasil yang sedikit berbeda ditemukan pada studi yang dilakukan oleh Gado dkk dimana justru proporsi penderita dispepsia lelaki lebih banyak dibandingkan dengan perempuan $(51 \%$ vs $49 \%) .{ }^{13}$ Studi yang dilakukan Gosh dkk menunjukkan proporsi usia dan jenis kelamin yang sedikit berbeda dimana penderita dispepsia yang menjalani endoskopi didominasi oleh usia $<40$ tahun $(69,4 \%)$ dan lelaki $(63,9 \%)$ meskipun alasan di balik hal ini tidak dijelaskan. ${ }^{14}$ Akan tetapi, pada studi yang dilakukan oleh Desai \& Mahapanta, dimana ditemukan perbandingan proporsi pria dan wanita sebesar 2,43:1 menjelaskan bahwa hal ini mungkin terjadi akibat adanya kecenderungan konsumsi alohol, dan rokok yang lebih tinggi pada pria, dimana hal ini merupakan salah satu dari kunci patogenesis disepepsia. ${ }^{15}$

Pada studi ini ditemukan bahwa dominasi klasifikasi dispepsia dipegang oleh dispepsia organik dengan proporsi $92.3 \%$ dan hanya sebagian kecil yang mengalami dispepsia fungsional. Hal ini berkebalikan dengan hasil studi dari Faintuch dkk menemukan bahwa sebanyak 66\% dari pasien yang mengalami dispepsia ternyata mengalami fungtional dispepsia sedangkan hanya $34 \%$ yang menderita dispepsia organik dengan proporsi terbanyak adalah esophagitis reflux disusul dengan ulkus peptikus. ${ }^{12}$ Studi yang dilakukan oleh Gado dkk juga menunjukkan hasil serupa dimana hanya $40 \%$ pasien dispepsia yang memiliki penyebab organik dengan hanya $20 \%$ diantaranya yang memiliki lesi signifikan pada gastrik dan duodenum. ${ }^{13}$

Dalam studi ini ditemukan bahwa hasil endoskopi yang paling sering muncul pada pasien dispepsia adalah gastritis, diikuti dengan hiatus hernia dan ulkus gaster. Hal ini juga sesuai dengan temuan Faintuch dkk dimana pada gambaran kelainan yang paling sering ditemukan pada endoskopi gaster adalah gastritis dengan proporsi $61 \% .^{12}$ Hasil yang hampir sejalan juga ditemukan pada studi yang dilakukan oleh Tytgat dkk dimana temuan endoskopi terbanyak pada pasien dispepsia adalah ulkus gaster dan gastroesofagitis.10 Desai \& Mahanta juga menemukan bahwa dua kasus tersering yang ditemukan pada pemeriksaan endoskopi pasien dispepsia adalah gastritis dan duodenonitis serta ulkus peptikus dengan proporsi masing-masing $24,8 \%$ dan $18,6 \%{ }^{15}$

Penulis melihat karakteristik temuan hasil endoskopi berdasarkan jenis kelamin dan usia. Ditemukan bahwa perempuan selalu memiliki frekuensi yang lebih tinggi pada setiap kelainan kecuali ulkus gaster, gastropati hipertensi portal dan hernia hiatal. Hal ini sejalan dengan temuan dari Mahmood dkk dimana persentase lelaki dengan ulkus gaster lebih tinggi dibandingkan dengan perempuan ( $1,83 \%$ vs $1,57 \%)$ begitu juga dengan persentase hiatus hernia $(3,9 \%$ vs $3,4 \%)$ di saat persentase kelainan lainnya didominasi oleh perempuan. Mereka juga menemukan gambaran endoskopi normal yang lebih banyak pada wanita dibandingkan dengan lelaki, dimana hal ini juga sejalan dengan hasil studi ini. ${ }^{16}$ Studi dari Grazyna dkk juga menemukan hasil serupa dimana pada kelainan ulserasi proporsi lelaki lebih banyak daripada perempuan dengan perbedaan jumlah yang signifikan secara statistik $(\mathrm{p}<0,005)$, begitu pula dengan hiatus hernia $(\mathrm{p}<0,005) .{ }^{17}$

Dalam studi ini juga ditemukan bahwa gambaran endoskopi normal lebih banyak ditemukan pada usia tua dibandingkan dengan usia muda, yang diperjelas dengan lebih banyaknya dispepsia fungsional pada kelompok usia muda dibandingkan dengan tua. Studi dari Mahmood dkk juga menemukan hasil serupa dimana temuan endoskopi tidak normal dan dispepsia organik lebih banyak ditemukan pada pasien dengan usia diatas 40 tahun. ${ }^{16}$ Dispepsia fungsional merupakan sekumpulan gejala yang diperkirakan berasal dari region gastroduodenal akan tetapi tidak terdapat bukti kelainan struktur pada bagian tersebut dalam pemeriksaan endoskopi. Berdasarkan sebuah studi, prevalensi penyakit ini semakin meningkat pada usia yang semakin muda sekitar $24.4 \%$ pada pasien berusia $<45$ tahun dan menurun menjadi $7 \%$ pada pasien $>65$ tahun. Hal ini diperkirakan disebabkan oleh lebih banyaknya kelainan struktur pada pasien usia tua terutama kelainan struktur yang berupa malignansi dibandingkan dengan usia muda. Dispepsia fungsional juga lebih dikaitkan dengan kelainan psikiatri dibandingkan dengan dispepsia organik, dimana kelainan psikiatri seperti gangguan cemas lebih sering ditemukan pada usia muda dibandingkan dengan usia tua. ${ }^{18}$ Hal serupa juga diungkapkan dalam studi dari Grazyna dimana prevalensi dispepsia fungsional paling tinggi pada populasi berusia 30-58 tahun dibandingkan yang lebih tua. ${ }^{17}$ 


\section{KESIMPULAN}

Karakteristik pasien dispepsia yang menjalani prosedur endoskopi di RSUP Sanglah pada periode 2015 adalah didominasi wanita dengan usia 41-60 tahun. Tiga besar temuan terbanyak dari endoskopi adalah gastritis, hiatus hernia dan ulkus peptikus. Pada saat dilakukan pemisahan karakteristik berdasarkan usia dan jenis kelamin, kelainan struktur lebih banyak ditemukan pada wanita dibandingkan pada pria kecuali pada kelainan ulus peptikum, hernia hiatus dan gastropati hipertensi portal. Pasien dengan usia lebih muda lebih banyak menderita dispepsia fungsional ketimbang dengan pasien pada kelompok usia yang lebih tua.

\section{KONFLIK KEPENTINGAN}

Tidak terdapat konflik kepentingan dalam penulisan laporan penelitian ini

\section{ETIKA PENELITIAN}

Persetujuan etik telah diperoleh oleh Komisi Etik, Fakultas Kedokteran, Universitas Udayana, Bali, Indonesia sebelum penelitian berjalan.

\section{PENDANAAN}

Tidak ada

\section{KONTRIBUSI PENULIS}

Anak Agung Gde Waisampayana Putra berkontribusi dalam penyusunan konsep penelitian, pengumpulan data penelitian, analisis data, hingga melaporkan hasil penelitian. I Dewa Nyoman Wibawa bertangung jawab sebagai pembimbing dalam penelitian ini.

\section{DAFTAR PUSTAKA}

1. Simadibrata M. dyspepsia and gastroesophageal reflux disease (GERD): is there any correlation? Acta Med Indones. 2009;41(4):222-7.

2. Suzuki RB, Cola RF, Cola LT, Ferrari CG, Ellinger F, Therezo AL, et al. Different risk factors influence peptic ulcer disease development in a Brazilian population. World J Gastroenterol. 2012;18(38):5404-11.
3. Putri CY, Arnelis, Asterina. Gambaran Klinis dan Endoskopi Saluran Cerna Bagian Atas Pasien Dispepsia di Bagian RSUP Dr. Djamil Padang. Jurnal Kesehatan Andalas. 2016;5(2):343-348

4. Abdullah M, Gunawan J. Dispepsia. Cermin Dunia Kedokteran. 2012;39(9):647-651.

5. Jose J. A Study of Aetiologies of Dyspepsia. IOSR Journal of Dental and Medical Sciences. 2015;14(9):06-09.

6. Talley NJ, Ford AC. Functional Dyspepsia. N Engl J Med. 2015;373(19):1853-63.

7. Tack J, Lee KJ. Patophysiology and treatment of functional dyspepsia. J Clin Gastroenterol. 2005;39(5 Suppl 3):S211-6.

8. Wallander MA, Johansson S, Ruigómez A, García Rodríguez LA, Jones R.. Dyspepsia in general practice: incidence, risk factors, comorbidity and mortality. Fam Pract. 2007;24(5):403-11.

9. Kahn Y, Mohanty S, Kumar H, Pandey S. Upper Gastro Instestinal Endoscopic Findings In Patients With Dyspepsia: Our Experience At Cims, Bilaspur, Chhattisgarh, India. IOSR Journal of Dental and Medical Sciences. 2014;13(5):8-9.

10. Tytgat GN. Role of endoscopy and biopsy in the work up of dyspepsia. Gut. 2002;50 Suppl 4:iv13-6.

11. ASGE Standards of Practice Committee, Shaukat A, Wang A, Acosta RD, Bruining DH, Chandrasekhara V, et al. The role of endoscopy in dyspepsia. Gastrointest Endosc. 2015;82(2):227-32.

12. Faintuch JJ, Silva FM, Navarro-Rodriguez T, Barbuti RC, Hashimoto CL, Rossini AR, et al. Endoscopic findings in univestigated dyspepsia. BMC Gastroenterol. 2014;14(19): 254-62

13. Gado A, Ebeid B, Abdelmoshsen A, Acon A. Endoscopic evaluation of patients with dyspepsia in a secondary referral hospital in Egypt. Alexandria Journal of Medicine. 2015;51(3): 179-84.

14. Gosh D, Barua U, Gosh C, Rahman M. Endoscopic evaluation of dyspeptic patients. Bangladesh Med J. 2013;42(3):82-84.

15. Desai SB, Mahanta BN. A Study of clinic endoscopic profile of patient presenting with dyspepsia. Clinical Epidemiology and Global Health. 2018;6(1):34-48

16. Mahmood K, Saedi MI, Mohammad R, Din ZU. Upper gastrointestinal endoscopic findings in patients with dyspepsia. Journal of Postgraduate Medical Institute. 2006;20(1):70-73.

17. Piotrowicz G, Stępień B, Rydzewska G. Socio demographic characteristics of patiemts with diagnosed functional dyspepsia. Prz Gastroenterol. 2013;8(6):354-65.

18. Brun R, Kuo B. Functional dyspepsia. Therap Adv Gastroenterol. 2010;3(3):145-64.

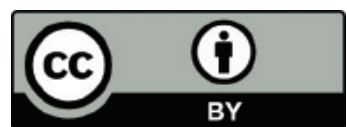

This work is licensed under a Creative Commons Attribution 